\title{
Disproportionate Organizational Injustice: A Close Look at Facilities Exempted from Indoor Smoking Laws in Canada
}

\section{Injustice organisationnelle disproportionnée : gros plan sur les installations exemptées des lois sur l'usage du tabac au Canada}

\author{
. \\ MOHAMMED AL-HAMDANI, MHA \\ Saint Mary's University \\ Halifax, NS
}

\begin{abstract}
Federal and provincial legislation bans smoking in indoor public spaces and workplaces, yet exemptions exist for residential facilities such as nursing homes and addiction treatment centres. In relying on ventilated smoking rooms, however, these organizations are failing to protect the health of their employees and clients. Increased use of risk messages regarding the harms of second-and third-hand smoke, together with enhanced nicotine replacement therapies for smokers, would rectify this disproportionate injustice. Such an approach must also recognize and counteract the efforts of the tobacco industry to block total indoor smoking bans.

\section{Résumé}

Les législations fédérale et provinciales interdisent l'usage du tabac dans les lieux de travail ou publics fermés, cependant il existe certaines exceptions pour les lieux situés dans une demeure tels que les maisons de soins et les centres de traitement de la toxicomanie. En utilisant des fumoirs dotés de systèmes de ventilation, ces organismes omettent d'assurer la protection de
\end{abstract}


la santé des employés et des clients. Un usage accru des messages sur les dangers du tabagisme passif et de la fumée tertiaire, de concert avec de meilleures thérapies de remplacement de la nicotine, pourrait corriger cette injustice disproportionnée. Une telle approche doit également reconnaître et contrer les efforts de l'industrie du tabac, qui visent à empêcher l'interdiction totale de l'usage du tabac dans les lieux fermés.

I N most Canadian provinces, organizations Can enaCt policies that extend smoking laws and bylaws. Unfortunately, the transformation from governmental laws to organizational policies is slow for facilities exempted from total indoor smoking bans.

Exempted facilities, such as nursing homes, have designated smoking rooms (DSRs) that allow patients to smoke. The gaps in extending legislation into organizational policies contribute to the fact that $19 \%$ of Canadians remain unprotected against second-hand smoke (SHS) in public areas and workplaces (Physicians for a Smoke-Free Canada 2007). Currently, a small number of exempted facilities in North America enact a total smoking ban (Goldsmith et al. 1991; Kotz 1993; Williams et al. 2005). The majority of exempted facilities allow DSRs, representing a missed opportunity for organizations to protect the health of their clients and employees.

\section{Reasons for Avoiding Indoor Smoking Extensions}

In general, it is not clear why exempted facilities have not extended governmental laws through the introduction of total indoor smoking bans. Four possible arguments could explain the existence of total indoor smoking ban exemptions.

1. The strongest argument in favour of these exemptions is the addictiveness of nicotine. If total indoor smoking bans are implemented, then the addiction of clients to nicotine could result in their experiencing unpleasant withdrawal symptoms and their consequent dissatisfaction with their stay at the facility. For this reason, exempted facilities might fear any possible conflicts with their clients and hence abandon the prospect of introducing total smoking bans.

2. A second argument in favour of exemptions pertains to addiction treatment facilities, where the premise for abandoning total indoor smoking bans is based on fears that banning smoking might affect the retention and hence the sobriety of clients. The argument with regard to sobriety and retention has mixed evidence. Most studies have demonstrated that the implementation of total smoking bans does not affect retention (Goldsmith et al. 1991; Kotz 1993; Williams et al. 2005), while at least one study suggested that total smoking bans reduced retention (Hammond and Gregoire 2011). These retention concerns could hamper the consideration of such bans.

3. The third argument in favour of exemptions stems from the fact that nursing homes and other exempted facilities are the primary places of residence for their clients. Policy mak- 
ers could be reluctant to implement total smoking bans in such facilities because clients might not be able to smoke elsewhere, resulting in possible conflicts between staff and clients (CDC 2006).

4. A fourth argument concerns the safety of patients who leave the facilities to smoke (Shultz et al. 2011). In general, patients express concerns over the effect of cold weather on their health. Patients claim that smoking outside when it's cold presents more health risks to them than smoking itself. Patients also express concerns over their safety when going outside to smoke alone. Additionally, patients in wheelchairs express difficulties in mobility after going out for a smoke, presenting a special problem for these patients.

\section{The Question of Disproportionate Injustice to Employees}

Organizational justice is the concept that refers to perceived fairness towards employees in the workplace in relation to outcomes and the policies that govern them (Gilliland 1994; Cohen-Charash and Spector 2001; Konovsky and Cropanzano 1991). To date, no studies have explored the perceived organizational justice towards employees in exempted facilities with DSRs, relative to facilities without DSRs, by exposing employees to SHS risk messages and then asking them to fill in an organizational justice questionnaire. Studies to evaluate a comparison of this nature are difficult; facilities are likely to hesitate to allow the measurement of organizational justice following exposure to such risk messages because of a fear that such a study could elicit negative behaviours from employees. Consequently, the important question of how just it is to expose employees in facilities with DSRs remains unanswered.

\section{The Health of Employees in Facilities with DSRs and Its Prioritization}

Among several competing social injustices, the exposure of employees to SHS in exempted facilities is considerable, yet remediable. DSRs in exempted facilities are ventilated, have warning signs outside the rooms and indicate that patients are allowed in there alone. These measures might reduce exposure to a hazard, but do not completely protect the health of employees. Even with displacement ventilation, claimed to reduce $90 \%$ of SHS, risk of exposure to air pollutants is 1,500 to 2,500 times higher than the acceptable level of risk for harmful air pollutants (Health and Safety Authority 2002). Ventilation rooms only reduce the exposure to SHS, which can travel from DSRs to other areas in the facilities (WHO 2011). Cigarette smoke saturates the furnishings in DSRs, where cleaning personnel are exposed to third-hand smoke (THS) that is re-emitted from the physical objects inside the designated room (Winickoff et al. 2010).

Recent studies have found that comprehensive smoking bans significantly reduce respirable suspended particulates (RSPs), a widely accepted SHS marker, in prisons and communities at large (Lee et al. 2009; Proescholdbell et al. 2008). The evidence of the reduction of SHS levels in prisons and the steadiness of retention rates in healthcare facilities after the implementation of total smoking bans demonstrates their practicality (Goldsmith et al. 1991; Kotz 1993; Lee et al. 2009; Proescholdbell et al. 2008; Williams et al. 2005). 


\section{Future Steps to Address the Issue}

There is a need for studies that track the improvement in air quality before and after the implementation of total indoor smoking bans in exempted facilities. Such studies will strengthen the case for total smoking bans by adding to the existing literature on the reduction of SHS in prisons following the implementation of comprehensive smoking bans (Proescholdbell et al. 2008). To facilitate the implementation of total smoking bans in exempted facilities, nicotine replacement therapies (NRTs) can help smoking clients cope with nicotine withdrawal, as NRTs are proven to increase the likelihood of quitting smoking.

The argument about exempted facilities being clients' primary residence and the possibility of conflicts between staff and residents is indefensible at the expense of exposing other clients and employees to SHS. Additionally, there is evidence suggesting that nursing homes with total smoking bans have fewer conflicts between staff and clients (CDC 2006).

Finally, concerns over the safety of patients are remediable via having a guard on site, encouraging smokers to go out for a smoke together, and offering constant NRT on site (Shultz et al. 2011). Wheelchair-bound patients could still have additional problems with mobility, but with constant NRT, they might be able to quit smoking and not have to go outside for a smoke. Restaurants, pubs and other indoor areas became smoke-free; currently exempted facilities should not be an exception that disproportionately harms their employees. The evidence of the harms of SHS and the imperfection of ventilated DSRs is well established. This evidence, along with the practicality of transforming laws into policies, places an ethical obligation on organizations to take action by enacting policies for total indoor smoking bans in order to protect their employees.

The tobacco industry's lobbying to shut down efforts for reducing exposure to SHS should be taken into consideration when trying to implement total smoking bans. There is evidence that the industry used scientific debates, media coverage expressing the opinions of the industry, and paid consultants to defeat efforts towards reducing SHS exposure (BryanJones and Bero 2003). Therefore, tobacco control advocates should counteract the industry's arguments with evidence and unravel some of its unethical practices aimed at blocking efforts to reduce exposure to SHS.

For example, the Legacy Tobacco Documents Library (LTDL) is a database for millions of tobacco industry documents that were secret prior to 1998, after which they became available in the public domain, as part of the Master Settlement Agreement (MSA). The LTDL database was created by the University of California, San Francisco and the Centre for Knowledge Management. The MSA is an agreement between the largest four tobacco companies and 46 American states where the companies agreed to a series of undertakings, including marketing restrictions and revealing some of their secretive internal documents. In exchange for these concessions, the companies are protected against state lawsuits and private lawsuits based on allegations of harm. The LTDL's database is a hub for documents that reveal the involvement of tobacco companies in lobbying against evidence aimed at reducing exposure to 
SHS. The results retrieved from such searches can be used to generate knowledge about the unethical practices of the tobacco industry.

\section{Conclusion}

Employees in facilities exempted from total indoor smoking bans are constantly exposed to SHS. This represents a form of organizational injustice. There is no evidence of negative consequences following enactment of total smoking bans, and the evidence of the harms of SHS is well grounded. The enactment of such policies represents a reasonable measure to protect the health of employees in exempted facilities. The arguments against total smoking ban exemptions are insufficient to abandon the prospect of measures that could protect employees from SHS and THS. The introduction of total indoor smoking bans could be effective if accompanied by the use of NRTs to reduce nicotine withdrawal and possible conflicts between employees and clients. Recognition of the tobacco industry's lobbying to prevent the implementation of measures that reduce exposure to SHS is essential in order to block its influence and implement total indoor smoking bans.

Correspondence may be directed to: Mohammed Al-hamdani, PhD in I/O Psychology (Candidate), Department of Psychology, Saint Mary's University, 923, Robie Street, Halifax, NS, B3H 3C3; e-mail:alhamdani.mohammed@gmail.com.

\section{REFERENCES}

Bryan-Jones, K. and L.A. Bero. 2003.“Tobacco Industry Efforts to Defeat Occupational Safety and Health Administration Indoor Air Quality Rule." American Journal of Public Health 93(4): 585-92.

Centres for Disease Control (CDC). 2006. The Health Consequences of Involuntary Exposure to Tobacco Smoke: A Report of the Surgeon General. Atlanta: Author. Retrieved September 29, 2012. <http://www.cdc.gov/tobacco/ data_statistics/sgr/2006>.

Cohen-Charash, Y. and P.E. Spector. 2001.“The Role of Justice in Organizations: A Meta-Analysis.” Organizational Behavior and Human Decision Processes 86(2): 278-321.

Gilliland, S.W. 1994. “Effects of Procedural and Distributive Justice on Reactions to a Selection System.” Journal of Applied Psychology 79(5): 691-715.

Goldsmith, R., R.D. Hurtand and J. Slade. 1991. "Development of Smoke-Free Chemical Dependency Units.” Journal of Addictive Diseases 11(2): 67-77.

Hammond, G.C. and T.K. Gregoire. 2011. “Breaking Ground in Treating Tobacco Dependence at a Women's

Treatment Center." Journal of Social Work Practice in the Addictions 11(1): 1-16.

Health and Safety Authority. 2002."Report on the Effect of Environmental Tobacco Smoke (ETS) in the Workplace." Retrieved May 10, 2012. <http://www.medicine.tcd.ie/public_health_primary_care/assets/pdf/ reports/ETS_Report.pdf >.

Lee, K., E.J. Hahn, H.E. Robertson, S. Lee, S.L. Vogel and M.J. Travers. 2009. “Strength of Smoke-Free Air Laws and Indoor Air Quality." Nicotine and Tobacco Research 11(4): 381-86.

Konovsky, M.A. and R. Cropanzano. 1991. "Perceived Fairness of Employee Drug Testing as a Predictor of Employee Attitudes and Job Performance." Journal of Applied Psychology 76(5): 685-98.

Kotz, M. 1993. "A Smoke-Free Chemical Dependency Unit: The Cleveland Clinic Experience." Journal of Substance Abuse Treatment 10(2): 125-31. 


\section{Disproportionate Organizational Injustice}

Physicians for a Smoke-Free Canada. 2007. "Protection from Second-Hand Smoke in Canada." Retrieved September 29, 2012. <http://www.smoke-free.ca/pdf_1/Q\&A-smokefreecommunities1.pdf>.

Proescholdbell, S.K., K.L. Foley, J. Johnston and S.H. Malek. 2008. “Indoor Air Quality in Prisons Before and After Implementation of a Smoking Ban Law." Tobacco Control 17: 123-27.

Schultz, A.S.H., B. Finegan, C.I.J. Nykiforuk and M.A. Kvern. 2011."A Qualitative Investigation of Smoke-Free Policies on Hospital Property." Canadian Medical Association Journal 183(18): 1334-44.

Williams, J.M., J. Foulds, M.B. Dwyer, B. Order-Connors, M. Springer, P. Gadde and D.M. Ziedonis. 2005.

"The Integration of Tobacco Dependence Treatment and Tobacco-Free Standards into Residential Addictions Treatment in New Jersey." Journal of Substance Abuse Treatment 28(4): 331-40.

Winickoff, J.P., M. Gottlieb and M. Mello. 2010. "Regulation of Smoking in Public Housing." New England Journal of Medicine 362(24): 2319-25.

World Health Organization (WHO). 2011 ."Effective Tobacco Control Measures." Retrieved September 29, 2012. $<$ http://www.paho.org/English/AD/SDE/RA/TobMeasures.htm>. 